\title{
Preadmission antidepressant use and bladder cancer: a population-based cohort study of stage at diagnosis, time to surgery, and surgical outcomes
}

Ellen Hollands Steffensen ${ }^{1 *}$ (D, Clint Cary ${ }^{2}$, Jørgen Bjerggaard Jensen ${ }^{3}$, Heidi Larsson ${ }^{4}$, Michael Weiner ${ }^{5}$ and Mette Nørgaard ${ }^{6}$

\begin{abstract}
Background: Among cancer patients, prior antidepressant use has been associated with impaired survival. This could be due to differences in stage at diagnosis, in receipt of treatment, or in treatment complications. The purpose of this study was, therefore, to examine if preadmission antidepressant use in patients with bladder cancer is associated with tumor stage at diagnosis, rate of cystectomy, and surgical outcomes, including survival.

Methods: We performed a registry-based cohort study including all patients with incident invasive bladder cancer in Denmark 2005-2015. Exposure was defined as redemption of two or more antidepressant prescriptions one year before cancer diagnosis. We compared tumor stage using logistic regression, postsurgical inpatient length of stay using linear regression, and other outcomes using Cox regression. All results were adjusted for age, sex, comorbidity, and marital status.

Results: Among 10,427 bladder cancer patients, 10\% were antidepressant users. At diagnosis, 51\% of users and $52 \%$ of non-users had muscle-invasive disease. However, upon adjustment for age, sex, comorbidity, and marital status, users had lower odds of muscle-invasive disease (adjusted odds ratio 0.86 ( $95 \%$ confidence interval (CI) 0 . 74-0.99)). Among patients with muscle-invasive disease, fewer users than non-users had surgery within three months (15\% vs. 24\%, adjusted hazard ratio (aHR) 0.75 (95\% Cl 0.59-0.95)). Of 2532 patients undergoing surgery, $6 \%$ were antidepressant users. Postsurgical inpatient length of stay did not differ between users and non-users. The 30-day cumulative incidence of readmission was higher for users (41\% vs. 33\%, aHR 1.33 (95\% Cl 1.05-1.67)), while the 90-day incidence of postoperative procedures was 44\% for users and 38\% for non-users (aHR 1.18 (95\% Cl 0.93-1.51)). One-year mortality was comparable in users (15\%) and non-users (14\%).

Conclusions: Antidepressant use in bladder cancer patients was associated with less advanced stage at diagnosis and lower rate of cystectomy. After cystectomy, users had higher rate of readmission and postoperative procedures than non-users, but we found no difference in length of stay or one-year mortality. The results point to the importance of differentiated clinical care according to individual patient characteristics.
\end{abstract}

Keywords: Urinary bladder neoplasms, Antidepressive agents, Delayed diagnosis, Cystectomy, Treatment outcome

\footnotetext{
* Correspondence: ehollandssteffensen@gmail.com

1Department of Clinical Epidemiology, Aarhus University Hospital, Aarhus,

Denmark

Full list of author information is available at the end of the article
}

(c) The Author(s). 2018 Open Access This article is distributed under the terms of the Creative Commons Attribution 4.0 International License (http://creativecommons.org/licenses/by/4.0/), which permits unrestricted use, distribution, and reproduction in any medium, provided you give appropriate credit to the original author(s) and the source, provide a link to the Creative Commons license, and indicate if changes were made. The Creative Commons Public Domain Dedication waiver (http://creativecommons.org/publicdomain/zero/1.0/) applies to the data made available in this article, unless otherwise stated. 


\section{Background}

As the ninth most commonly diagnosed cancer worldwide, bladder cancer caused a reported 165,000 deaths globally in 2012 [1]. Recommended standard treatment for muscleinvasive and high-risk non-muscle-invasive tumors is radical cystectomy, a procedure with 30-day complication rates between $24 \%$ and $73 \%$ [2]. Comorbidity raises complication risk [3], and bladder cancer patients are increasingly comorbid [4], with increased medication use including antidepressants as a consequence. The overall use of antidepressants increased by a mean of 40 defined daily doses/ 1000/day across Europe in the period 1980-2009 [5].

Although increasingly prescribed for neuropathic pain and sleep disorders, antidepressants are mostly prescribed for depression [6]. In a Danish setting, use of antidepressants detects patients suffering from a depression with a specificity of $94 \%$ to $97 \%$ [7]. This makes prescription data about antidepressants suited for identification of patients with depression in Denmark, where more than $90 \%$ of such patients are treated by general practitioners [7]; the treatment in these cases is not recorded in hospital registries.

In a recent Danish cohort study of patients with various types of cancer, prior antidepressant use was associated with a $30 \%$ increase in one-year mortality [8]. The study supports prior studies reporting an elevated mortality in patients with depression who developed various cancers [9-11], pancreatic cancer [12], colon cancer [13], or prostate cancer [14]. Diagnostic delay, reduced likelihood of appropriate treatment, or treatment complications may explain an increased mortality in antidepressant users. However, studies of delay in diagnosis of breast, prostate, colorectal, bladder, lung, skin, uterine, and pancreatic cancer for patients with depression show conflicting results [8-10, 12]. Prior antidepressant use was not associated with more advanced bladder cancer stage in the recent Danish work [8]. Although previous studies have reported a lower likelihood of appropriate cancer treatment in patients with prior or existing depression in a number of cancers combined [9], as well as pancreatic [12], colon [13], or prostate cancer [14], this has not been examined in patients with bladder cancer. The reported increase in one-year mortality among patients with cancer who used antidepressants before cancer diagnosis [8] is of concern and more detailed studies are needed to clarify underlying mechanisms.

Therefore, the aim of this nationwide population-based cohort study was to investigate whether antidepressant use initiated before invasive bladder cancer diagnosis was associated with more advanced cancer at time of diagnosis or time of surgery, lower rate of cystectomy, and a more complicated postoperative course reflected in length of hospital stay, readmission, postoperative procedures and mortality.

\section{Methods}

We performed a nationwide register-based cohort study including all patients diagnosed with incident invasive bladder cancer in Denmark from 2005 through 2015. The Danish population, approximately 5.6 million inhabitants, has access to tax-supported healthcare, with free access to hospital-based and primary medical care provided by the Danish National Health Service [15]. All inhabitants in Denmark have a unique Civil Personal Register (CPR) number, which is recorded along with administrative and medical information in registries and databases and allows for person-specific linkage of information [16].

\section{Data sources}

From the Danish National Patient Registry (DNPR), we retrieved diagnosis and procedure codes and associated dates. The DNPR has tracked all somatic hospitalizations in Denmark since 1977 and outpatient and emergency room visits to hospitals since 1995. Recorded data include CPR numbers, dates of admission and discharge, and up to 20 diagnoses, classified according to the International Classification of Diseases, tenth revision (ICD-10) since 1994 [17]. We ascertained information on tumor pathology from The Danish National Pathology Registry, which contains descriptions of pathological specimens and has a coverage of almost 100\% [18]. The registry was established in 1997, and data from earlier years have been added [18]. We defined exposure status using data from the Danish National Database of Reimbursed Prescriptions [19]. This registry encompasses information on all redeemed prescriptions from 2004 onwards, including date of redemption and Anatomical Therapeutic Chemical (ATC) code. Finally, the Danish Civil Registration System provided data on marital and vital status. This database contains nearly complete, demographic data and is updated daily [16].

\section{Study population}

We identified patients with incident, histologically verified invasive bladder cancer (thus not including patients with carcinoma in situ or pTa tumors) based on ICD-10 diagnosis codes (C67) and bladder cancer pathology (Additional file 1: Table S1). To increase the probability of truly incident cases we excluded patients fulfilling these criteria between 1995 and 2004.

For the surgical outcome analyses, we identified patients with bladder cancer and a recorded cystectomy excluding patients who received intended curative radiation therapy before cystectomy (Additional file 1: Table S1).

\section{Exposure, outcome measures, and covariates}

We defined individuals as exposed ('antidepressant users') if they filled two or more antidepressant prescriptions (ATC code N06A) on separate occasions in the year 
preceding bladder cancer diagnosis. Using this definition we sought to reduce the number of non-adherent patients in the exposure group. Individuals filling one prescription or less are termed 'non-users'. Patients who filled an antidepressant prescription after bladder cancer diagnosis, but not in the year before, were treated as non-users.

Stage at diagnosis was defined as muscle-invasive (pT2 + ) or non-muscle-invasive (pT1), and stage at cystectomy as organ confined (pT0-T2 and pN0) or non-organ confined (pT3-T4 or $\mathrm{pN}+$ ).

We compared the cumulative incidence of cystectomy within three months following a diagnosis of muscle-invasive disease. We chose three months as a clinically relevant end of follow-up based on prior work [20]. Following surgery, we assessed outcomes expected to reflect a complicated postsurgical course: length of hospital stay, acute readmission to a somatic hospital within 30 days after discharge from the primary admission, 90-day rate of postoperative procedures, and all-cause mortality at one and three years. We defined postoperative procedures as any invasive procedure within 90 days after cystectomy (any NOMESCO Classification of Surgical Procedures code).

Based on existing literature we included as potential confounders: age, sex, marital status at diagnosis, Charlson Comorbidity Index (CCI) score [21] (excluding bladder cancer), and alcohol-related disorders. We identified comorbidities from DNPR within 10 years before cancer diagnosis (Additional file 2: Table S2) [22].

\section{Statistical methods}

Patients' characteristics at bladder cancer diagnosis were summarized according to exposure groups. Continuous variables were either categorized or described by their median value and interquartile range. For categorical variables, we computed proportions of individuals at each categorical level by exposure group.

We examined the association between antidepressant use and stage at diagnosis (muscle-invasive $(\mathrm{pT} 2+)$ or non-muscle-invasive (pT1)) or surgery (organ confined (pT0-T2 and pN0) or non-organ confined (pT3-T4 or $\mathrm{pN}+$ )) using logistic regression, adjusting for age at diagnosis (included as an unrestricted spline with four knots in the analysis of stage at diagnosis and squared in stage at surgery), sex, CCI score (0,1-2, 3+), alcohol-related disorders (yes/no), and marital status at diagnosis (mar$\mathrm{ried} /$ not married). The analysis of stage at surgery excluded patients receiving neoadjuvant chemotherapy, which was introduced nationwide in Denmark in 2013 (Additional file 1: Table S1).

Due to missing data for tumor stage at diagnosis and at surgery, two sensitivity analyses were performed to increase the proportion of individuals with stage data: we restricted the analysis of stage at diagnosis to patients diagnosed during 2011-2015, and we repeated the analysis of stage at surgery including the latest stage recorded before surgery, if stage at surgery was missing.

For the analysis of time to surgery, we followed patients not receiving neoadjuvant chemotherapy from the date on which muscle invasiveness was first detected until cystectomy, death, emigration, end of the three months of follow-up, or 11 April 2016, whichever came first. Follow-up for postoperative procedures began at date of surgery while follow-up for readmission began at discharge. For both events, follow-up ended at event of interest, death, emigration, end of the 30-day or 90-day follow-up, or 11 April 2016, whichever came first.

We computed the cumulative incidence of cystectomy and used Cox proportional hazards regression to investigate the association between antidepressant use and cystectomy. Here, death and curative-intended radiation therapy were treated as competing risks.

We used Cox proportional hazards regression to investigate associations between antidepressant use and readmission and postoperative procedures adjusting as described for the logistic regression of stage at surgery. Death was considered competing risk. Length of hospital stay was compared between groups using a multiple linear regression model including covariates as in the logistic regression of stage at diagnosis.

For the mortality analysis, we followed patients from date of surgery until death, emigration, end of the oneyear or three-year follow-up or 19 April 2016, whichever came first. We used the Kaplan-Meier estimator and compared mortality using Cox regression adjusting as described for the logistic regression of stage at surgery.

Additionally, we investigated whether neoadjuvant chemotherapy, stage at surgery, and type of surgery (open or laparoscopic and robot-assisted, (Additional file 1: Table S1)) mediated surgical outcome differences between exposure groups by addition of each of these variables individually to the regression models described above.

For all Cox regressions, the assumption of proportional hazards was assessed by log-minus-log plots.

All analyses were performed using Stata version 14 (StataCorp LP, College Station, Texas).

\section{Results}

We identified 10,427 patients with incident invasive bladder cancer during 2005 through 2015 (Fig. 1). In the cohort, 1079 (10\%) were antidepressant users. At presentation, antidepressant users were less likely to be married and had more comorbidity than non-users (Table 1).

\section{Stage at diagnosis and at surgery}

At diagnosis, analysis of data from $79 \%$ of patients for whom $\mathrm{pT}$ stage data were available showed comparable 


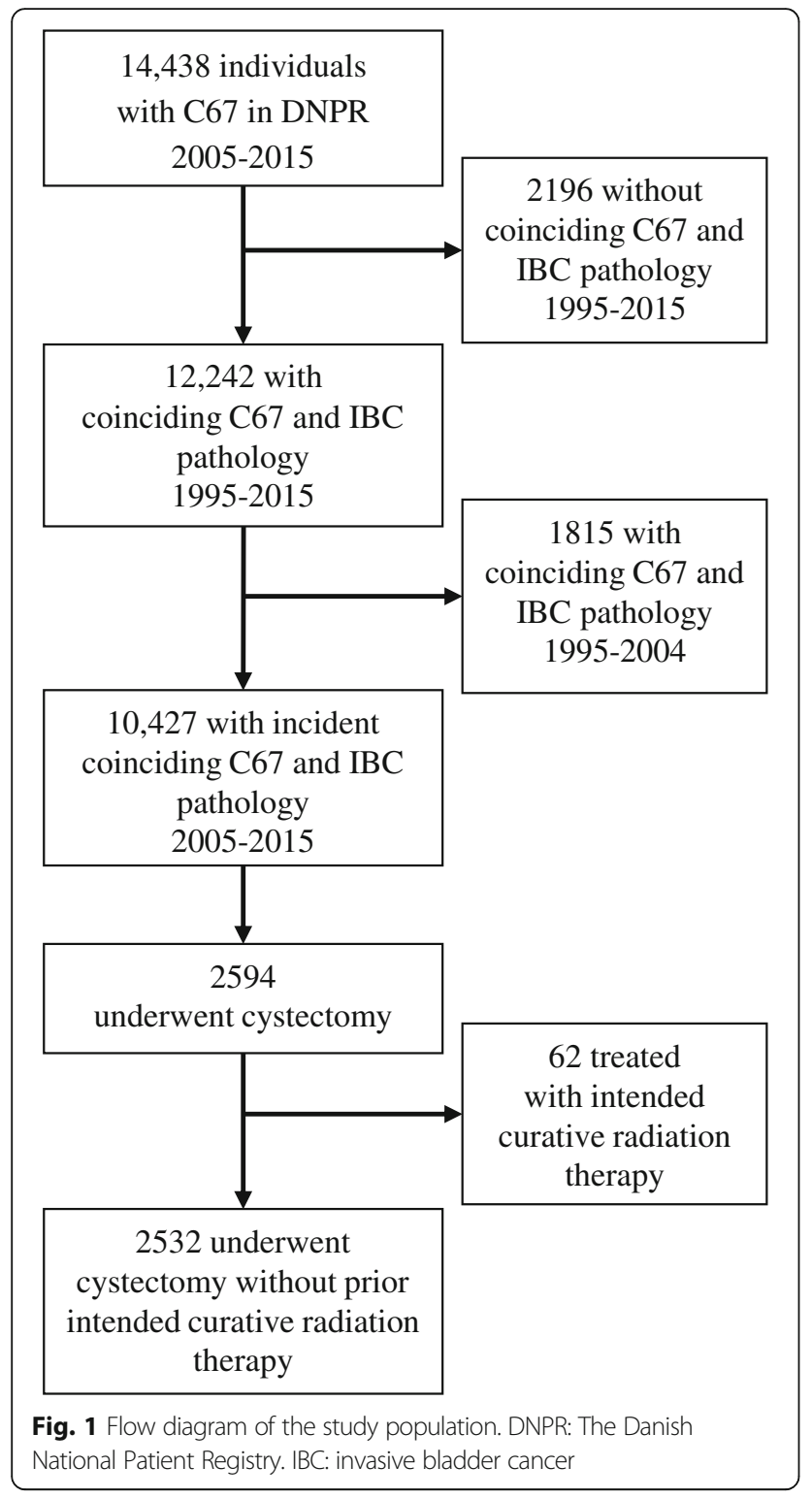

proportions of muscle-invasive disease in antidepressant users and non-users, but upon adjustment, antidepressant users had lower odds of muscle-invasiveness compared with non-users (adjusted odds ratio 0.86 (95\% CI 0.740.99)) (Table 2). Restricting the analysis to patients diagnosed during 2011 through 2015, where 93\% had stage information, yielded an adjusted odds ratio of 0.87 (95\% CI 0.71-1.05).

At cystectomy, $62 \%$ of antidepressant versus $57 \%$ of non-users had non-organ confined disease (Table 3). The adjusted odds ratio for non-organ confined disease was 1.16 (95\% CI $0.78-1.74$ ) in the $71 \%$ of patients with tumor-stage information at surgery. Additionally adjusting for time to surgery yielded an odds ratio of 1.18 (95\% CI 0.79-1.77). Replacing missing values with the
Table 1 Patient characteristics at diagnosis according to use of antidepressants before cancer diagnosis

\begin{tabular}{|c|c|c|c|c|}
\hline & \multicolumn{2}{|c|}{ Non-users } & \multicolumn{2}{|c|}{ AD users } \\
\hline & $n$ & $\%$ & $n$ & $\%$ \\
\hline Total & 9348 & 89.7 & 1079 & 10.3 \\
\hline Median age (IQR) (years) & 72.5 & $66.0-79.8$ & 74.4 & $67.8-82.3$ \\
\hline \multicolumn{5}{|l|}{ Age group (years) } \\
\hline $18-49$ & 224 & 2.4 & 22 & 2.0 \\
\hline $50-59$ & 814 & 8.7 & 85 & 7.9 \\
\hline $60-69$ & 2554 & 27.3 & 235 & 21.8 \\
\hline 70-79 & 3475 & 37.2 & 378 & 35.0 \\
\hline $80-$ & 2281 & 24.4 & 3539 & 33.3 \\
\hline \multicolumn{5}{|l|}{ Sex } \\
\hline Male & 7036 & 75.3 & 647 & 60.0 \\
\hline Female & 2312 & 24.7 & 432 & 40.0 \\
\hline \multicolumn{5}{|l|}{ Marital status } \\
\hline Married & 5549 & 59.4 & 532 & 49.3 \\
\hline Widowed & 1836 & 19.6 & 320 & 29.7 \\
\hline Divorced & 1233 & 13.2 & 145 & 13.4 \\
\hline Never married & 730 & 7.8 & 82 & 7.6 \\
\hline \multicolumn{5}{|l|}{ Charlson Comorbidity Index score } \\
\hline Low (0) & 4703 & 50.3 & 334 & 31.0 \\
\hline Medium (1-2) & 3124 & 33.4 & 437 & 40.5 \\
\hline High (3+) & 1521 & 16.3 & 308 & 28.5 \\
\hline Alcohol-related disorders & 191 & 2.0 & 68 & 6.3 \\
\hline \multicolumn{5}{|l|}{ Year of cancer diagnosis } \\
\hline $2005-2007$ & 2563 & 27.4 & 271 & 25.1 \\
\hline 2008-2010 & 2555 & 27.3 & 283 & 26.2 \\
\hline $2011-2013$ & 2527 & 27.0 & 314 & 29.1 \\
\hline 2014-2015 & 1703 & 18.2 & 211 & 19.6 \\
\hline \multicolumn{5}{|l|}{ Stage of cancer at diagnosis } \\
\hline Non-muscle-invasive (pT1) & 3538 & 37.8 & 423 & 39.2 \\
\hline Muscle-invasive (pT2+) & 3854 & 41.2 & 437 & 40.5 \\
\hline Missing & 1956 & 20.9 & 219 & 20.3 \\
\hline Cystectomy & 2370 & 25.4 & 162 & 15.0 \\
\hline Neoadjuvant chemotherapy & 222 & 9.4 & 15 & 9.3 \\
\hline Intended curative radiation therapy & 1145 & 12.3 & 114 & 10.6 \\
\hline
\end{tabular}

All patients $(n=10,427)$ were diagnosed with incident invasive bladder cancer during 2005 through 2015. $A D$ antidepressant, IQR interquartile range

latest stage recorded before surgery resulted in an adjusted odds ratio of 1.19 (95\% CI 0.84-1.69).

\section{Time to surgery}

We identified 4953 patients with muscle-invasive bladder cancer. The cumulative incidence of cystectomy within three months from the date on which muscle invasiveness was first detected was lower for antidepressant users than 
Table 2 Odds ratios for muscle-invasive bladder cancer at diagnosis comparing antidepressant users to non-users

\begin{tabular}{|c|c|c|c|c|c|c|c|c|c|}
\hline & \multicolumn{6}{|c|}{ Complete case analysis } & \multicolumn{3}{|l|}{$2011-2015$} \\
\hline & \multicolumn{2}{|c|}{ Muscle-invasive (pT2+) } & \multicolumn{2}{|c|}{ Non-muscle-invasive (pT1) } & \multirow{2}{*}{$\begin{array}{l}\text { Unadjusted } \\
\text { odds ratio } \\
(95 \% \mathrm{Cl})\end{array}$} & \multirow{2}{*}{$\begin{array}{l}\text { Adjusted }^{a} \\
\text { odds ratio } \\
(95 \% \mathrm{Cl})\end{array}$} & & \multirow{2}{*}{$\begin{array}{l}\text { Unadjusted } \\
\text { odds ratio } \\
(95 \% \mathrm{Cl})\end{array}$} & \multirow{2}{*}{$\begin{array}{l}\text { Adjusted }^{a} \\
\text { odds ratio } \\
(95 \% \mathrm{Cl})\end{array}$} \\
\hline & $n$ & $\%$ & $n$ & $\%$ & & & & & \\
\hline Non-users $(n=7392)$ & 3854 & 52.1 & 3538 & 47.9 & Ref. & Ref. & Non-users $(n=3938)$ & Ref. & Ref. \\
\hline AD users $(n=860)$ & 437 & 50.8 & 423 & 49.2 & $\begin{array}{l}0.95 \\
(0.82-1.09)\end{array}$ & $\begin{array}{l}0.86 \\
(0.74-0.99)\end{array}$ & AD users $(n=490)$ & $\begin{array}{l}0.96 \\
(0.79-1.16)\end{array}$ & $\begin{array}{l}0.87 \\
(0.71-1.05)\end{array}$ \\
\hline
\end{tabular}

Results of complete case analysis (2005-2015) and when restricting the analysis to 2011 through $2015 . A D$ antidepressant, $C l$ confidence interval. ${ }^{a}$ Adjusted for age, sex, $\mathrm{CCl}$, alcohol-related disorders, and marital status

non-users (Fig. 2). The difference remained apparent after adjustment (adjusted hazard ratio 0.75 (95\% CI 0.59 0.95)) (Table 4).

\section{Surgical outcomes}

We identified 2532 cystectomies of which 698 (27.6\%) were robot-assisted. Among cystectomized patients, $162(6 \%)$ were antidepressant users. Table 5 presents estimates of associations between antidepressant use and surgical outcomes. Median follow up from surgery to death, loss to follow up, or end of study was 2.6 years (interquartile range 1.1 to 5.5 years).

Median duration of postsurgical stay did not differ between antidepressant users and non-users.

With a cumulative incidence of $41 \%$, antidepressant users were more likely to be acutely readmitted within 30 days after discharge, compared with non-users (adjusted hazard ratio 1.33 (95\% CI 1.05-1.67)). We observed no difference in type of department for readmission between antidepressant users and non-users (results not shown). The diagnoses related to readmission were similar among exposure groups and largely reflected postoperative complications (results not shown).

Antidepressant users' 90-day cumulative incidence of postoperative procedures was $44 \%$ compared with $38 \%$ among non-users (adjusted hazard ratio 1.18 (95\% CI 0.93-1.51)). The types of postoperative procedures were comparable among antidepressant users and non-users and mainly represented procedures related to complications to the cystectomy and urinary diversion-the five most common being: percutaneous nephrostomy, repair of wound dehiscence in urological surgery, percutaneous drainage of intraperitoneal abscess, percutaneous drainage of peritoneal cavity, and nephrostomy.

Overall one-year all-cause mortality after surgery was 14.5\% (95\% CI 13.1-15.9\%). One- and three-year mortality showed no difference between exposure groups after adjustment.

Repeating all surgical outcome analyses additionally adjusting for neoadjuvant chemotherapy, stage at cystectomy, or type of surgery changed estimates by less than 5\% (Additional file 3: Table S3).

\section{Discussion}

In this nationwide population-based cohort study, we found that patients with bladder cancer who filled at least two antidepressant prescriptions in the year before cancer diagnosis were less likely to present with muscle-invasive disease at diagnosis (i.e. they had lower odds of muscle-invasive disease relative to non-users upon adjustment). Users also had a lower rate of cystectomy in case of muscle-invasive disease. Following surgery, antidepressant users and non-users had comparable length of stay. However, we observed a slightly higher risk of postoperative procedures within 90 days and a higher 30-day readmission rate after surgery in antidepressant users than in non-users. Still, users' all-cause mortality was not different from non-users at one and three years.

We observed similar proportions of patients with muscle-invasive cancer at diagnosis among antidepressant users and non-users. However, this observation was likely confounded since antidepressant users had lower odds of

Table 3 Odds ratios for non-organ confined cancer at cystectomy comparing antidepressant users to non-users

\begin{tabular}{|c|c|c|c|c|c|c|c|c|c|}
\hline & \multicolumn{6}{|c|}{ Complete case analysis } & \multicolumn{3}{|l|}{ Including prior stages } \\
\hline & \multicolumn{2}{|c|}{$\begin{array}{l}\text { Non-organ confined } \\
\text { (pT3-T4 or } \mathrm{pN}+\text { ) }\end{array}$} & \multicolumn{2}{|c|}{$\begin{array}{l}\text { Organ confined } \\
\text { (pT0-T2 and pN0) }\end{array}$} & \multirow{2}{*}{$\begin{array}{l}\text { Unadjusted } \\
\text { odds ratio } \\
(95 \% \mathrm{Cl})\end{array}$} & \multirow{2}{*}{$\begin{array}{l}\text { Adjusted }^{\mathrm{a}} \\
\text { odds ratio } \\
(95 \% \mathrm{Cl})\end{array}$} & & \multirow{2}{*}{$\begin{array}{l}\text { Unadjusted } \\
\text { odds ratio } \\
(95 \% \mathrm{Cl})\end{array}$} & \multirow{2}{*}{$\begin{array}{l}\text { Adjusted }^{a} \\
\text { odds ratio } \\
(95 \% \mathrm{Cl})\end{array}$} \\
\hline & $\bar{n}$ & $\%$ & $n$ & $\%$ & & & & & \\
\hline Non-users $(n=1521)$ & 859 & 56.5 & 662 & 43.5 & Ref. & Ref. & Non-users $(n=2081)$ & Ref. & Ref. \\
\hline AD users $(n=111)$ & 69 & 62.2 & 42 & 37.8 & $\begin{array}{l}1.27 \\
(0.85-1.88)\end{array}$ & $\begin{array}{l}1.16 \\
(0.78-1.74)\end{array}$ & AD users $(n=142)$ & $1.29(0.92-1.81)$ & $\begin{array}{l}1.19 \\
(0.84-1.69)\end{array}$ \\
\hline
\end{tabular}

Results of complete case analysis and when replacing missing values for cancer stage with the latest stage observed before surgery. $A D$ antidepressant, $C l$ confidence interval. ${ }^{a}$ Adjusted for age, sex, $\mathrm{CCl}$, alcohol-related disorders, and marital status 


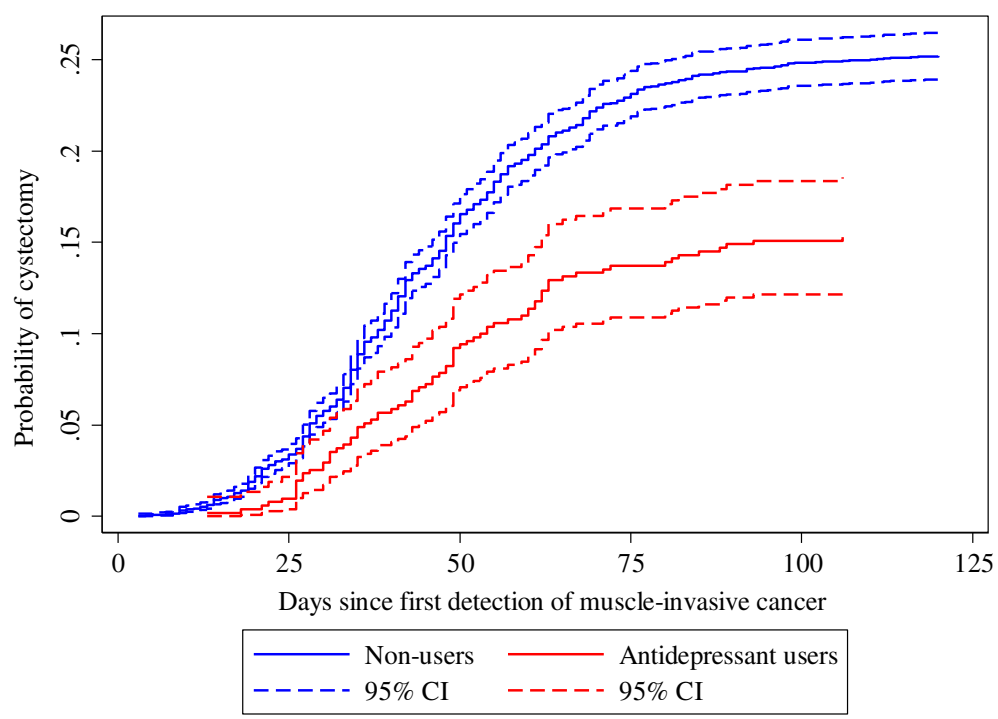

Fig. 2 Cumulative incidence of cystectomy within three months from the first detection of muscle-invasive disease. Cl: Confidence interval

muscle-invasive disease upon adjustment for age, sex, comorbidity, and marital status. Our result is unexpected since depression has been associated with advanced stage at cancer presentation $[8,12]$. One possible explanation is an enhanced likelihood of cancer detection due to increased utilization of health care by antidepressant users [23]. Study setting may add to this: access to the tax-funded Danish health care services is free [15], minimizing the risk of patient delay in diagnosis due to patients' financial situation or constraints. However, Sun et al. found that Danish patients with breast, colorectal, or prostate cancer who were using antidepressants presented in an advanced stage [8]. This suggests that mechanisms underlying diagnostic delay may differ between cancer types. In bladder cancer, hematuria may be so concerning to patients that it leads to cancer diagnosis even if patients are impaired by depression. In other cancers, symptoms may be less alarming, or perhaps symptoms are considered caused by depression, leading to a diagnostic delay in patients with depression who develop cancer.

Previous studies have found a lower likelihood of treatment in cancer patients with prior depression [9, 12-14]. This is in line with our finding of antidepressant users' lower rate of cystectomy. Patient-related factors associated with decline of curative cancer treatment include patients' perceived low quality of patient-physician communication
[24], concern about side effects [25], and expected low quality of life after surgery [24] all of which may be exaggerated in antidepressant users. Another explanation could be that a larger proportion of antidepressant users than non-users received palliative care rather than radical cystectomy. We must note, however, that we did not have information on all clinical features and patient characteristics contributing to treatment decision.

We observed a high rate of postoperative procedures compared with prior studies reporting 90-day reoperation rates in the range $14-33 \%$ [2]. The discrepancy is likely explained by the fact that we included all types of procedures (not solely complication related procedures) performed 90 days after cystectomy. We note that the estimate in this analysis is somewhat imprecise, given that the 95\% confidence interval includes one. Higher rates of readmission and, potentially, postoperative procedures among antidepressant users suggest a more complicated postsurgical course, while the lack of difference in length of stay speaks against any major difference. In prior studies, surgical patients with depressive symptoms had impaired wound healing and higher risk of infections [26, 27]. Our results are consistent with these findings, if antidepressant users had depressive symptoms at the time of surgery.

Table 4 Cumulative incidence and hazard ratio of cystectomy for patients with muscle-invasive disease comparing antidepressant users to non-users

\begin{tabular}{|c|c|c|c|c|}
\hline & Cystectomized, $n$ & Three months cumulative incidence, \% (95\% Cl) & Unadjusted HR (95\% CI) & Adjusted $^{\mathrm{a}} \mathrm{HR}(95 \% \mathrm{Cl})$ \\
\hline Non-users $(n=4443)$ & 1082 & $24.3(23.1-25.6)$ & Ref. & Ref. \\
\hline AD users $(n=510)$ & 76 & $14.7(11.8-18.0)$ & $0.60(0.48-0.76)$ & $0.75(0.59-0.95)$ \\
\hline
\end{tabular}

The cumulative incidence and hazard ratio of cystectomy is determined within three months from the first detection of muscle-invasive disease. $A D$ antidepressant, $\mathrm{HR}$ hazard ratio, $\mathrm{Cl}$ confidence interval. ${ }^{a}$ Adjusted for age, sex, $\mathrm{CCl}$, alcohol-related disorders, and marital status 
Table 5 Surgical outcomes among patients undergoing radical cystectomy by antidepressant use before cancer diagnosis

\begin{tabular}{|c|c|c|}
\hline Surgical outcome & Non-users & $A D$ users \\
\hline \multicolumn{3}{|l|}{ Length of stay (LOS) } \\
\hline $\begin{array}{l}\text { Days admitted, median } \\
\text { (IQR) }\end{array}$ & $10(7-13)$ & $9(8-13)$ \\
\hline $\begin{array}{l}\text { Unadjusted ratio of median LOS } \\
(95 \% \mathrm{Cl})\end{array}$ & Ref. & $1.03(0.95-1.13)$ \\
\hline $\begin{array}{l}\text { Adjusted }^{\mathrm{a}} \text { ratio of median LOS } \\
(95 \% \mathrm{Cl})\end{array}$ & Ref. & $1.02(0.93-1.12)$ \\
\hline \multicolumn{3}{|l|}{ 30-day acute readmission } \\
\hline Total, n & 2241 & 151 \\
\hline Readmitted, $\mathrm{n}$ & 747 & 62 \\
\hline Cumulative incidence, \% (95\% Cl) & $33.4(31.4-35.3)$ & $41.1(33.2-48.8)$ \\
\hline Unadjusted HR (95\% Cl) & Ref. & $1.36(1.08-1.71)$ \\
\hline Adjusted $^{\mathrm{a}} \mathrm{HR}(95 \% \mathrm{Cl})$ & Ref. & $1.33(1.05-1.67)$ \\
\hline \multicolumn{3}{|l|}{ 90-day postoperative procedure } \\
\hline Total, n & 2370 & 162 \\
\hline Procedures, n & 908 & 72 \\
\hline Cumulative incidence, \% (95\% Cl) & $38.3(36.4-40.3)$ & $44.4(36.7-51.9)$ \\
\hline Unadjusted HR (95\% Cl) & Ref. & $1.19(0.93-1.51)$ \\
\hline Adjusted* HR (95\% Cl) & Ref. & $1.18(0.93-1.51)$ \\
\hline \multicolumn{3}{|l|}{ One-year all-cause mortality } \\
\hline Total, n & 2370 & 162 \\
\hline Deaths, n & 330 & 24 \\
\hline Cumulative incidence, \% (95\% Cl) & $14.4(13.1-16.0)$ & $15.0(10.3-21.6)$ \\
\hline Unadjusted HR (95\% Cl) & Ref. & $1.05(0.69-1.58)$ \\
\hline Adjusted $^{\mathrm{a}}$ HR $(95 \% \mathrm{Cl})$ & Ref. & $0.96(0.63-1.46)$ \\
\hline \multicolumn{3}{|l|}{ Three-year all-cause mortality } \\
\hline Total, n & 2370 & 162 \\
\hline Deaths, $\mathrm{n}$ & 650 & 52 \\
\hline Cumulative incidence, \% (95\% Cl) & $31.3(29.3-33.4)$ & $35.4(28.1-43.8)$ \\
\hline Unadjusted HR (95\% CI) & Ref. & $1.16(0.88-1.54)$ \\
\hline Adjusted $^{\mathrm{a}} \mathrm{HR}(95 \% \mathrm{Cl})$ & Ref. & $1.02(0.77-1.36)$ \\
\hline
\end{tabular}

In contrast to prior work [8], we did not observe an association between antidepressant use and all-cause mortality in patients with cancer. Possible explanations may be that we restricted the survival analysis to patients undergoing surgery and that selection for surgery differed between antidepressant users and non-users. Antidepressant users and non-users who underwent surgery are a selected group of patients with bladder cancer. Differences in comorbidity are likely to be equalized because of the selection resulting in comparable survival. Also, Sun et al. [8] found that the increased mortality among antidepressant users depended on time of antidepressant initiation. This may contribute to the discrepancy between our studies. Another aspect to consider is severity of depression: generally, antidepressant users were probably less severely depressed than individuals included in earlier studies based on secondary psychiatric care data [10,11], because these previous studies did not include patients with milder depression treated by general practitioners.

A strength of the current study is that by using register data, we were able to include all patients in Denmark with invasive bladder cancer during the study period. Also, we were able to control for differences in comorbidity in contrast to previous studies $[9,10]$. We did not rely on self-report of exposure and we achieved essentially complete follow-up, thereby increasing generalizability. To reduce the risk of misclassification due to medication non-adherence, we required the exposed patients to have filled at least two prescriptions for antidepressants.

The study results must, however, be interpreted bearing in mind a number of limitations. Our analyses did not take into account indications for readmission and postoperative procedures. However, we only observed small differences between antidepressant users and non-users in types of postoperative procedures and readmission, and most procedure codes and readmission diagnosis codes reflected complications related to cystectomy.

We emphasize that use of antidepressants does not always indicate depression, since antidepressants are sometimes prescribed for other conditions. As such, our findings may not be directly comparable to studies investigating patients with a depression diagnosis. Also, some non-users may have suffered from a depression not treated by antidepressants. This could weaken associations between antidepressant use and outcomes such as time to cystectomy or postoperative outcomes. Prior studies based on a diagnosis of depression might have experienced a comparable misclassification of exposure due to undiagnosed depression or depression not recorded in registries [9-14].

We note that antidepressant users were generally more comorbid than non-users; a potential confounding effect we accounted for by adjusting for CCI. However, we cannot rule out the possibility of residual confounding due to e.g. comorbidity not recorded in registries. Also, we lacked information on certain additional potential confounders, such as detailed clinical characteristics, smoking, alcohol use, and socioeconomic status. A previous study, however, found no clear association between socioeconomic status and radical cystectomy [28]. Although we restricted the analysis of time to surgery to patients with muscle-invasive disease, we cannot rule out that exposure groups differed with regard to lymph node status and/or distant metastases. If more antidepressant users had distant metastases, this could explain their lower rate of cystectomy. However, 
antidepressant users had less advanced cancer at diagnosis, suggesting that they were not more likely to have metastases compared with non-users. Moreover, we did not observe any mortality difference between groups, which would have been expected in case of unequal proportions of patients with distant metastases. Smoking increases the risk of surgical complications [29], and may in part confound our findings on readmission and postoperative procedures. However, estimates changed very little upon adjustment for other covariates (age, sex, comorbidity, and marital status). This leads us to believe that confounding by smoking does not completely explain the observed associations. Smoking is associated with more advanced stage of bladder cancer at diagnosis [30]. Thus, if antidepressant users were more often smokers, the lower stage at diagnosis observed among them would be unexpected. On the other hand, if antidepressant users were less often smokers, our observation of no difference in mortality after surgery could be confounded by smoking. Altogether, we cannot exclude the possibility that the inability to adjust for smoking leads to residual confounding.

Our findings suggest that patients with bladder cancer using antidepressants before diagnosis may be a subgroup worth special attention-especially in relation to receipt of treatment and postsurgical care. This also points to the importance of differentiated clinical care according to individual characteristics and individual needs. For example, patients with high levels of comorbidities preoperatively, dementia, depression, etc. are subgroups who we should devote more effort to in terms of preoperative preparation and closer postoperative care following discharge. In line with this, future studies may focus on other patient subgroups and evaluate aspects in relation to receipt of treatment and treatment outcomes as such knowledge is a prerequisite for individualized clinical care.

\section{Conclusions}

In conclusion, this nationwide population-based cohort study using Danish register data found that antidepressant use before invasive bladder cancer diagnosis was associated with less advanced stage of cancer at diagnosis. Among patients with muscle invasive disease, we observed lower rate of cystectomy in antidepressant users, and after surgery higher rate of readmission and, potentially, higher rate of postoperative procedures, but not prolonged length of stay or increased all-cause mortality. Our findings indicate that antidepressant users who develop bladder cancer may require increased medical attention.

\section{Additional files}

Additional file 1: Table S1. Coding of bladder cancer, cystectomy, intended curative radiation therapy, and neoadjuvant chemotherapy. (DOCX $15 \mathrm{~kb}$ )
Additional file 2: Table S2. ICD-10 codes defining Charlson Comorbidity Index (CCI) diseases and alcohol-related disorders. (DOCX 14 kb)

Additional file 3: Table S3. Surgical outcomes by antidepressant use with additional adjustments. (DOCX $14 \mathrm{~kb}$ )

\section{Abbreviations}

AD: Antidepressant; ATC: Anatomical Therapeutic Chemical; CCl: Charlson Comorbidity Index; CPR: Civil Personal Register; DNPR: The Danish National Patient Registry; HR: Hazard ratio; ICD-10: International Classification of Diseases, tenth revision; OR: Odds ratio

\section{Acknowledgements}

Not applicable.

\section{Funding}

This study was supported by grants from The Danish Council for Independent Research | Medical Sciences (grant number 6110-00040), The University of Copenhagen Foundation for Medical Students (journal number A4996), and Christian Larsen \& Judge Ellen Larsens Foundation (journal number 5011780). None of the funding sources were involved in design of the study, data collection and analysis, interpretation of results, writing of the manuscript, or in the decision to submit the manuscript for publication.

\section{Availability of data and materials}

The datasets generated and/or analysed during the current study are not publicly available since the data do not belong to the authors but to the Danish Ministry of Health, and the authors are not permitted to share them, except in aggregate (as, for example, in a publication). However, interested parties can obtain the data on which the study was based by submitting a research protocol to the Danish Data Protection Agency (Datatilsynet) and then, once Data Protection Agency permission has been received, applying to the Ministry of Health's Research Service (Forskerservice) at forskerservice@ssi.dk.

\section{Authors' contributions}

EHS and MN designed the study with contributions from CC, JBJ, and MW. $\mathrm{HL}$ assisted in data management. EHS performed the statistical analyses and drafted the first version of the manuscript. All authors interpreted the data, read and approved the final manuscript.

\section{Authors' information}

MW is Chief of Health Services Research and Development at the Richard L. Roudebush Veterans Affairs Medical Center in Indianapolis, Indiana, USA. The views expressed in this article are those of the authors and do not necessarily represent the views of the U.S. Department of Veterans Affairs.

\section{Ethics approval and consent to participate}

The Danish Data Protection Agency approved the study (journal number 2014-54-0922). Studies based solely on data from the Danish national registers do, by Danish legislation, not require approval from the Danish Health Research Ethics committees, as study participants are never contacted, and consent is not required for the use of register information.

Consent for publication

Not applicable.

\section{Competing interests}

The authors declare that they have no competing interests.

\section{Publisher's Note}

Springer Nature remains neutral with regard to jurisdictional claims in published maps and institutional affiliations.

\section{Author details}

'Department of Clinical Epidemiology, Aarhus University Hospital, Aarhus, Denmark. ${ }^{2}$ Department of Urology, Indiana University School of Medicine, Indianapolis, IN, USA and Regenstrief Institute, Inc, Indianapolis, IN, USA. ${ }^{3}$ Department of Urology, Aarhus University Hospital, Aarhus, Denmark and Department of Clinical Medicine, Health, Aarhus University, Aarhus, Denmark. ${ }^{4}$ Department of Clinical Epidemiology, Aarhus University Hospital, Aarhus, 
Denmark and The Danish National Registries - a National Quality Improvement Programme (RKKP), Aarhus, Denmark. ${ }^{5}$ Indiana University School of Medicine, Indianapolis, IN, USA and Regenstrief Institute, Inc, Indianapolis, IN, USA. ${ }^{6}$ Department of Clinical Epidemiology, Aarhus

University Hospital, Aarhus, Denmark.

Received: 1 February 2018 Accepted: 11 October 2018

Published online: 24 October 2018

\section{References}

1. Ferlay J, Soerjomataram I, Dikshit R, Eser S, Mathers C, Rebelo M, Parkin DM, Forman D, Bray F. Cancer incidence and mortality worldwide: sources, methods and major patterns in GLOBOCAN 2012. Int J Cancer. 2015: 136(5):E359-86.

2. Novara G, Catto JW, Wilson T, Annerstedt M, Chan K, Murphy DG, Motttrie A, Peabody JO, Skinner EC, Wiklund PN, et al. Systematic review and cumulative analysis of perioperative outcomes and complications after robot-assisted radical cystectomy. Eur Urol. 2015;67(3):376-401.

3. Fairey A, Chetner M, Metcalfe J, Moore R, Todd G, Rourke K, Voaklander D, Estey E. Associations among age, comorbidity and clinical outcomes after radical cystectomy: results from the Alberta urology institute radical cystectomy database. J Urol. 2008;180(1):128-34

4. Lund L, Jacobsen J, Clark P, Borre M, Norgaard M. Impact of comorbidity on survival of invasive bladder cancer patients, 1996-2007: a Danish populationbased cohort study. Urology. 2010;75(2):393-8.

5. Gusmao R, Quintao S, McDaid D, Arensman E, Van Audenhove C, Coffey C Varnik A, Varnik P, Coyne J, Hegerl U. Antidepressant utilization and suicide in Europe: an ecological multi-National Study. PLoS One. 2013;8(6):e66455.

6. Noordam R, Aarts N, Verhamme KM, Sturkenboom MC, Stricker BH, Visser LE. Prescription and indication trends of antidepressant drugs in the Netherlands between 1996 and 2012: a dynamic population-based study. Eur J Clin Pharmacol. 2015;71(3):369-75.

7. Thielen K, Nygaard E, Andersen I, Rugulies R, Heinesen E, Bech P, Bultmann $U$, Diderichsen F. Misclassification and the use of register-based indicators for depression. Acta Psychiatr Scand. 2009;119(4):312-9.

8. Sun Y, Vedsted P, Fenger-Gron M, Wu CS, Bech BH, Olsen J, Benros ME, Vestergaard M. Cancer mortality in people treated with antidepressants before Cancer diagnosis: a population based cohort study. PLoS One. 2015; 10(9):e0138134.

9. Kisely $\mathrm{S}$, Crowe E, Lawrence D. Cancer-related mortality in people with mental illness. JAMA Psychiatry. 2013;70(2):209-17.

10. Chang CK, Hayes RD, Broadbent MT, Hotopf M, Davies E, Moller H, Stewart R. A cohort study on mental disorders, stage of cancer at diagnosis and subsequent survival. BMJ Open. 2014:4(1):e004295.

11. Batty GD, Whitley E, Gale CR, Osborn D, Tynelius P, Rasmussen F. Impact of mental health problems on case fatality in male cancer patients. $\mathrm{Br} J$ Cancer. 2012;106(11):1842-5.

12. Boyd CA, Benarroch-Gampel J, Sheffield KM, Han Y, Kuo YF, Riall TS. The effect of depression on stage at diagnosis, treatment, and survival in pancreatic adenocarcinoma. Surgery. 2012;152(3):403-13.

13. Baillargeon J, Kuo YF, Lin YL, Raji MA, Singh A, Goodwin JS. Effect of mental disorders on diagnosis, treatment, and survival of older adults with colon cancer. J Am Geriatr Soc. 2011;59(7):1268-73.

14. Prasad SM, Eggener SE, Lipsitz SR, Irwin MR, Ganz PA, Hu JC. Effect of depression on diagnosis, treatment, and mortality of men with clinically localized prostate cancer. J Clin Oncol Off J Am Soc Clin Oncol. 2014; 32(23):2471-8

15. Olejaz M, Juul Nielsen A, Rudkjobing A, Okkels Birk H, Krasnik A, HernandezQuevedo C. Denmark health system review. Health Syst Transit. 2012; 14(2):1-192.

16. Schmidt $M$, Pedersen $L$, Sorensen HT. The Danish civil registration system as a tool in epidemiology. Eur J Epidemiol. 2014;29(8):541-9.

17. Schmidt M, Schmidt SA, Sandegaard JL, Ehrenstein V, Pedersen L, Sorensen HT. The Danish National Patient Registry: a review of content, data quality, and research potential. Clin Epidemiol. 2015;7:449-90.

18. Bjerregaard B, Larsen OB. The Danish pathology register. Scand J Public Health. 2011;39(7 Suppl):72-4.

19. Johannesdottir SA, Horvath-Puho E, Ehrenstein V, Schmidt M, Pedersen L, Sorensen HT. Existing data sources for clinical epidemiology: the Danish National Database of reimbursed prescriptions. Clin Epidemiol. 2012;4: 303-13.
20. May M, Nitzke T, Helke C, Vogler H, Hoschke B. Significance of the time period between diagnosis of muscle invasion and radical cystectomy with regard to the prognosis of transitional cell carcinoma of the urothelium in the bladder. Scand J Urol Nephrol. 2004;38(3):231-5.

21. Charlson ME, Pompei $P$, Ales $K L$, Mackenzie CR. A new method of classifying prognostic comorbidity in longitudinal studies: development and validation. J Chronic Dis. 1987:40(5):373-83.

22. Thygesen SK, Christiansen CF, Christensen S, Lash TL, Sorensen HT. The predictive value of ICD-10 diagnostic coding used to assess Charlson comorbidity index conditions in the population-based Danish National Registry of patients. BMC Med Res Methodol. 2011;11:83.

23. Bock J-O, Luppa M, Brettschneider C, Riedel-Heller S, Bickel H, Fuchs A, Gensichen J, Maier W, Mergenthal K, Schäfer I, et al. Impact of depression on health care utilization and costs among multimorbid patients - results from the MultiCare cohort study. PLoS One. 2014;9(3):e91973.

24. Cykert S, Dilworth-Anderson P, Monroe MH, Walker P, McGuire FR, CorbieSmith $G$, Edwards $\sqcup$, Bunton AJ. Factors associated with decisions to undergo surgery among patients with newly diagnosed early-stage lung cancer. Jama. 2010;303(23):2368-76.

25. Gorin MA, Soloway CT, Eldefrawy A, Soloway MS. Factors that influence patient enrollment in active surveillance for low-risk prostate cancer. Urology. 2011;77(3):588-91.

26. Doering LV, Moser DK, Lemankiewicz W, Luper C, Khan S. Depression, healing, and recovery from coronary artery bypass surgery. Am J Crit Care. 2005;14(4):316-24.

27. Gordon RJ, Weinberg AD, Pagani FD, Slaughter MS, Pappas PS, Naka Y, Goldstein DJ, Dembitsky WP, Giacalone JC, Ferrante J, et al. Prospective, multicenter study of ventricular assist device infections. Circulation. 2013; 127(6):691-702

28. Goossens-Laan CA, Leliveld AM, Verhoeven RH, Kil PJ, de Bock GH, Hulshof MC, de Jong IJ, Coebergh JW. Effects of age and comorbidity on treatment and survival of patients with muscle-invasive bladder cancer. Int J Cancer. 2014:135(4):905-12.

29. Gajdos C, Hawn MT, Campagna EJ, Henderson WG, Singh JA, Houston T. Adverse effects of smoking on postoperative outcomes in cancer patients. Ann Surg Oncol. 2012;19(5):1430-8.

30. van Roekel EH, Cheng KK, James ND, Wallace DM, Billingham LJ, Murray PG, Bryan RT, Zeegers MP. Smoking is associated with lower age, higher grade, higher stage, and larger size of malignant bladder tumors at diagnosis. Int J Cancer. 2013:133(2):446-54.

\section{Ready to submit your research? Choose BMC and benefit from:}

- fast, convenient online submission

- thorough peer review by experienced researchers in your field

- rapid publication on acceptance

- support for research data, including large and complex data types

- gold Open Access which fosters wider collaboration and increased citations

- maximum visibility for your research: over $100 \mathrm{M}$ website views per year

At $\mathrm{BMC}$, research is always in progress.

Learn more biomedcentral.com/submissions 